\title{
Cleaning Products and Air Fresheners: Emissions and Resulting Concentrations of Glycol Ethers and Terpenoids
}

\author{
Brett C. Singer $^{* a, b}$, Hugo Destaillats ${ }^{b}$, Alfred T. Hodgson ${ }^{b}$, and William W Nazaroff ${ }^{b, c}$ \\ ${ }^{a}$ Atmospheric Sciences and ${ }^{b}$ Indoor Environment Departmenst, Environmental Energy \\ Technologies Division, Lawrence Berkeley National Laboratory, Berkeley, CA 94720, USA \\ ${ }^{c}$ Department of Civil and Environmental Engineering, University of California, Berkeley, \\ California 94720-1710, USA
}

\begin{abstract}
Experiments were conducted to quantify emissions and concentrations of glycol ethers and terpenoids from cleaning product and air freshener use in a $50-\mathrm{m}^{3}$ room ventilated at $\sim 0.5 \mathrm{~h}^{-1}$. Five cleaning products were applied full-strength (FS); three were additionally used in dilute solution. FS application of pine-oil cleaner (POC) yielded 1-h concentrations of 10-1300 $\mu \mathrm{g} \mathrm{m}^{-3}$ for individual terpenoids, including $\alpha$-terpinene (90-120), d-limonene (1000-1100), terpinolene (900-1300), and $\alpha$-terpineol (260-700). One-hour concentrations of 2-butoxyethanol and/or dlimonene were 300-6000 $\mathrm{gg} \mathrm{m}^{-3}$ after FS use of other products. During FS application including rinsing with sponge and wiping with towels, fractional emissions (mass volatilized / dispensed) of 2-butoxyethanol and d-limonene were 50-100\% with towels retained, 25-50\% when towels were removed after cleaning. Lower fractions (2-11\%) resulted from dilute use. Fractional emissions of terpenes from FS use of POC were $35-70 \%$ with towels retained, $20-50 \%$ with towels removed. During floor cleaning with dilute solution of POC, 7-12\% of dispensed terpenes were emitted. Terpene alcohols were emitted at lower fractions: $7-30 \%$ (FS, towels retained), 2-9\% (FS, towels removed), and 2-5\% (dilute). During air-freshener use, d-limonene, dihydromyrcenol, linalool, linalyl acetate, and $\beta$-citronellol) were emitted at $35-180 \mathrm{mg} \mathrm{d}^{-1}$ over three days while air concentrations averaged 30-160 $\mathrm{g} \mathrm{g} \mathrm{m}^{-3}$.
\end{abstract}

\section{PRACTICAL IMPLICATIONS}

While effective cleaning can improve the healthfulness of indoor environments, this work shows that use of some consumer cleaning agents can yield high levels of volatile organic compounds, including glycol ethers - which are regulated toxic air contaminants - and terpenes that can react with ozone to form a variety of secondary pollutants including formaldehyde and ultrafine particles. Persons involved in cleaning, especially those who clean occupationally or often, might encounter excessive exposures to these pollutants owing to cleaning product emissions. Mitigation options include screening of product ingredients and increased ventilation during and after cleaning. Certain practices, such as the use of some products in dilute solution versus full-strength and the prompt removal of cleaning supplies from occupied spaces, can reduce emissions and exposures to 2-butoxyethanol and other volatile constituents. Also, it may

\footnotetext{
*E-mail: BCSinger@lbl.gov; Fax: 510-486-5928
} 
be prudent to limit use of products containing ozone-reactive constituents when indoor ozone concentrations are elevated either because of high ambient ozone levels or because of the indoor use of ozone-generating equipment.

\section{KEYWORDS}

Exposure, indoor air chemistry, sorption, toxic air contaminants, volatile organic compounds

\section{INTRODUCTION}

The indoor use of cleaning products and air fresheners can lead to inhalation exposures to primary emissions of volatile product constituents and to secondary pollutants formed as these constituents react (e.g. with ozone) in the indoor environment. Certain of these inhalation exposures raise potential health concerns, as reviewed by Wolkoff et al. (1998) and by Nazaroff and Weschler (2004).

One class of compounds for which exposure concerns arise is ethylene-based glycol ethers, which are widely used as solvents in cleaning products. The US Environmental Protection Agency classified glycol ethers as hazardous air pollutants (HAP) under the 1990 Clean Air Act Amendments. The agency recently delisted 2-butoxyethanol (2-BE, CAS No. 111-76-2, also known as ethylene glycol monobutyl ether) from the HAP group of glycol ethers. The action was substantiated by the agency's determination that "emissions, ambient concentrations, bioaccumulation, or deposition of [2-BE] may not reasonably be anticipated to cause adverse human health or environmental effects" (USEPA, 2003 and 2004). The exposure assessment used to support the decision considered only inhalation exposure owing to emissions to ambient air. The potentially higher concentrations and exposures associated with 2-BE emissions from products used indoors were not addressed. The California Air Resources Board lists glycol ethers as a class of toxic air contaminants (TAC). Within its TAC identification program, California has established reference exposure levels (REL) for several specific glycol ethers, including 2-BE with a value for acute (1-h) exposures of $14 \mathrm{mg} \mathrm{m}^{-3}$ (OEHHA, 1999). The federal reference concentration for chronic inhalation exposure (RfC) is comparable at $13 \mathrm{mg} \mathrm{m}^{-3}$ (http://www.epa.gov/iris/subst/0500.htm).

Also of potential concern in cleaning products and air fresheners are terpene hydrocarbons, terpene alcohols, and other related unsaturated compounds. These chemicals, frequently derived from plant oils, are used as scenting agents in many consumer products and as active solvents in certain cleaning products. Many of these compounds react rapidly with ozone, producing formaldehyde (Fan et al., 2003), hydrogen peroxide (Li et al., 2002), hydroxyl radical (Weschler and Shields, 1997), and secondary organic aerosol (Weschler and Shields, 1999; Wainman et al., 2000; Liu et al., 2004; Sarwar et al., 2004). Recent studies suggest that reactive chemistry between terpenes and ozone produces upper airway and eye irritants (Wolkoff et al., 2000; Klenø and Wolkoff, 2004).

Little is known about the chemical emissions and constituent gas-phase concentrations that result from the use of cleaning products and air fresheners. Gibson et al. (1991) conducted 
simulated-use experiments to characterize emissions and concentrations of diethylene glycol monobutyl ether from hard-surface cleaning products. Zhu et al. (2001) used small-chamber experiments to characterize emissions of 2-BE from selected consumer products, including some cleaning agents. Wainman et al. (2000) reported concentrations of d-limonene from simulated use of a lemon-scented furniture polish. Several groups have investigated the secondary particle production associated with terpene-ozone interactions in which the terpenes were emitted from use of air fresheners or cleaning products (Wainman et al., 2000; Sarwar et al., 2004; Liu et al., 2004; Destaillats et al., 2005).

In this paper, we report on experiments investigating the indoor air emissions and concentrations of glycol ethers, terpenes and related compounds associated with cleaning product and air freshener use. For six commercial products, the chemical composition was measured directly and a series of simulated use experiments was conducted. In these experiments, timedependent concentrations of target constituents were measured, and associated time-integrated emissions were calculated.

\section{METHODS}

\subsection{Product selection}

The six products examined in this study were selected using a multistage screening process, considering the following key criteria. (1) Products are readily available to consumers through retail outlets. (2) Products are either known or expected to contain substantial levels of reactive terpenes, terpene alcohols, other unsaturated compounds, or ethylene-based glycol ethers. (3) The set of products includes at least one each of glass/surface cleaner, general purpose cleaner, and air freshener.

In the first stage, a shelf survey of cleaning products and air fresheners was conducted in five chain retail outlets in the San Francisco Bay Area. From the resulting list, we selected fifty candidate products and reviewed product labels and available material safety data sheets to determine or infer the presence of target constituents. Twenty-one of the products subsequently were experimentally screened to identify and semi-quantitatively determine their chemical compositions. These measurements were made by means of volatilizing small aliquots of the products into Tedlar bags and sampling the air in the bags. Six products were selected from this group for further study. Summary information for the selected products is presented in Table 1. These products include one glass/surface cleaner (GLC-1), four general-purpose cleaners (GPC1 through GPC-4), and one scented-oil air freshener (AFR-1).

\subsection{Composition determination by solvent dilution}

Composition was determined by analysis of a dilute solution of each product in methanol. A small aliquot of the liquid product $(1.5-10 \mu \mathrm{L})$ was combined in a conical vial with 5-10 mL HPLC-grade methanol. The vial was sealed, then sonicated or shaken gently by hand. An aliquot of solution (2-35 $\mu \mathrm{L}$ ) was withdrawn by syringe and injected into a Tenax tube under a $100 \mathrm{~mL}$ 
$\min ^{-1}$ helium purge maintained for 10-15 min to volatilize the methanol. The sample was then analyzed as described in $§ 2.6$.

\subsection{Experimental chamber and materials}

Experiments were conducted in a $50-\mathrm{m}^{3}$ chamber designed to simulate a typical residential environment. Construction materials include wood framing with plywood underlying the floor, two walls and ceiling. The chamber walls and ceiling are finished with $64 \mathrm{~m}^{2}$ of gypsum wallboard coated with low-VOC paint. The plywood subfloor was covered with aluminum sheeting. A portion of the floor $\left(3.9 \mathrm{~m}^{2}\right)$ was covered with vinyl composition tiles to provide a surface for mopping. Molding was attached at the tile perimeter to contain cleaning solution. A laminate table with top surface area of $1.16 \mathrm{~m}^{2}$ was placed in the middle of the room.

Chamber air was mixed with four small axial fans mounted at $1 / 3$ and 2/3 of ceiling height on poles 1 to $1.5 \mathrm{~m}$ from room corners. Ventilation was mechanically provided, with outdoor air passed through a bed of activated carbon to remove organic gases and ozone. The air-exchange rate was fixed and checked during each experiment by measuring the concentration decay of injected $\mathrm{SF}_{6}$ tracer gas. Temperature in the chamber was controlled by thermostatic regulation of the air temperature of the building in which the chamber is contained. Relative humidity (RH) was not controlled, but experiments were limited to days in which $\mathrm{RH}$ was in the range of 40$70 \%$ at the start. Temperature and $\mathrm{RH}$ were measured continuously using Vaisala sensors; output was recorded as 1-h averages.

\subsection{Application protocols}

Table 2 summarizes the 18 simulated-use experiments conducted in the $50-\mathrm{m}^{3}$ chamber. Cleaning protocols outlined in Table 2 were developed to simulate two general methods of product use: (1) full-strength application, and (2) dilute solution use. Three of the generalpurpose cleaners (GPC-1, GPC-3 and GPC-4) instruct use at varied levels of dilution depending on application, including full-strength use for tough jobs, or as needed. Two of these (GPC-3 and GPC-4) implicitly encourage full-strength use as they are packaged in trigger-spray bottles. These three products were evaluated in both full-strength and dilute form. GLC-1 and GPC-2 are packaged in trigger spray bottles that recommend full-strength use on a variety of surfaces; these products were evaluated exclusively in a full-strength application. The scented-oil air freshener was used as directed.

The full-strength surface cleaning protocol was designed to simulate varied applications including cleaning, degreasing, or disinfecting of hard surface counters, tabletops, stovetops, or glass. Products were applied full-strength to a $0.56-\mathrm{m}^{2}$ section of the laminate tabletop, providing a cleaned surface to room volume ratio of $\sim 0.01 \mathrm{~m}^{2} \mathrm{~m}^{-3}$. Four products (GLC-1, GPC-2, GPC-3, and GPC-4) were dispensed by spraying $\sim 6 \mathrm{~mL}\left(\sim 11 \mathrm{~g} \mathrm{~m}^{-2}\right)$ from the product container. For GPC-1, $10 \mathrm{~mL}\left(\sim 18 \mathrm{~g} \mathrm{~m}^{-2}\right)$ was dispensed by pipette. These amounts are intended to represent high but realistic use rates, based on the results of product-use surveys (see §2.5). After application, the product was left undisturbed for $\sim 1 \mathrm{~min}$. In two experiments ( $\mathrm{L}$ and $\mathrm{M}$; Table 2 ), the wetted surface was wiped clean with paper towels. In other experiments, the surface was 
scrubbed using a wetted and loosely wrung $114 \times 68 \times 15$-mm cellulose sponge backed with abrasive material (3M Scotch-Brite ${ }^{\circledR}$ heavy-duty scrub sponge). After scrubbing, the tabletop was dried with paper towels and the sponge was rinsed in a bucket of clean, warm water ( $\mathrm{T}=45$ $55^{\circ} \mathrm{C}$ ). Next, water was applied to the tabletop with the sponge to simulate rinsing. Finally, the tabletop was dried with a second set of paper towels. In experiments A-D, the paper towels were removed from the chamber upon completion of the cleaning activity. In experiments E-M, paper towels were deposited in a wastebasket with plastic liner and remained in the chamber for $24 \mathrm{~h}$. The full application procedure, including scrub, wipe, rinse, and wipe steps was completed in approximately 2.5 min during experiments A-D and 3.5 min in experiments E-K. The spray and wipe procedure (experiments L-M) was completed in $2 \mathrm{~min}$.

Materials were weighed before and after each use starting with experiment E. The wetted sponge was wrung to a mass of $56 \pm 2 \mathrm{~g}(\mu \pm \sigma)$ before scrubbing and weighed $50 \pm 2 \mathrm{~g}$ after use; a net $6 \pm 3 \mathrm{~g}$ of water thus was transferred from the sponge to the cleaning surface during this step. The paper towels used after scrubbing absorbed $9 \pm 2 \mathrm{~g}$ of solution. The rinse sponge weighed $61 \pm 6$ and $52 \pm 3 \mathrm{~g}$ before and after use, delivering $9 \pm 3 \mathrm{~g}$ of solution. The paper towels used after rinsing absorbed $7 \pm 2 \mathrm{~g}$ of solution. By the end of experiments in which paper towels remained in the chamber, those used after scrubbing and rinsing retained $1.9 \pm 1.4$ and $0.5 \pm 0.3 \mathrm{~g}$, respectively.

The second protocol was intended to represent general use of dilute cleaning solutions. The protocol included solution preparation, wet mopping, and dry mopping of floor tiles. The $3.9 \mathrm{~m}^{2}$ area of tiles provided a cleaned surface to room volume ratio of $\sim 0.08 \mathrm{~m}^{2} \mathrm{~m}^{-3}$. The solution was prepared inside the chamber by measuring and dispensing the designated amount of full-strength cleaner (experiments $\mathrm{N}-\mathrm{Q}$ ) into $\sim 4 \mathrm{~L}$ of warm water $\left(\mathrm{T}=45-55^{\circ} \mathrm{C}\right)$ in a $10 \mathrm{~L}$ plastic bucket. A 2layer sponge mop (Quickie Home Pro) measuring $223 \times 87 \times 25 \mathrm{~mm}$ was used to spread the solution while applying pressure to simulate cleaning. Six mop strokes (back and forth) were used to apply the solution to each quadrant of the floor. The mop was submerged then removed and tilted to drain excess solution before mopping each quadrant. The wrung mop was used to soak up solution in 24 half-strokes; additional wringing occurred after each 4-6 strokes. Finally the mop was wrung and guided over the entire tiled area to complete the dry-mopping phase. The remaining solution was poured into a second bucket within the chamber to simulate disposal. The procedure lasted 7-7.5 min and ended with the removal of all cleaning materials from the chamber. The net amount of solution used during cleaning was $\sim 90-120 \mathrm{~g}$, corresponding to $\sim 2-$ $3 \%$ of the prepared mopping solution.

In experiment $\mathrm{R}$, the scented oil air freshener was plugged into an extension cord mounted to one of the table legs. The product container was weighed at elapsed times of 2, 8, 21, 29, 51, and $73 \mathrm{~h}$ after use began.

\subsection{Product application rates}

Two surveys were conducted to determine appropriate product application rates. Subjects were recruited from LBNL staff via e-mail, telephone and personal invitation. In the first survey, each of 25 subjects was instructed to use a trigger-spray product (GPC-3) to clean a $0.93 \mathrm{~m}^{2}$ (10 $\mathrm{ft}^{2}$ ) section of laminate tabletop. Although the tabletop was clean, subjects were asked to imagine 
it to be "moderately dirty," e.g. after preparing dinner, but having no "caked-on food or stains that would result from weeks or months without cleaning." The tabletop was wiped completely dry between subjects. A single observer provided instruction, recorded the mass of the bottle before and after use and the number and approximate extent of trigger pulls for each subject. The second survey measured the application rate of two disinfection products, including GPC-1. Each of 11 subjects was instructed to use the products to disinfect two identical, clean laminated tabletops, each having top dimensions of $61 \times 191 \mathrm{~cm}$ for a surface area of $1.16 \mathrm{~m}^{2}\left(12.5 \mathrm{ft}^{2}\right)$. Subjects were provided with an almost full bottle of each product and encouraged to review the directions. Also provided was a bucket of clean water, a sponge, and paper towels. An observer weighed the product bottle before and after each use and recorded subject comments. The table and sponge were rinsed and dried between subjects.

\subsection{VOC sampling and chemical analysis}

Air samples for analysis of volatile organic compounds (VOCs) were collected onto sorbent tubes (P/N CP-16251, Varian Inc.) packed with Tenax TA and Carbosieve SIII or with Tenax TA only. Air was drawn directly onto the sorbent tubes, which were fixed horizontally at least 30 $\mathrm{cm}$ from the chamber wall. Background samples were collected before each experiment at $\sim 100$ $\mathrm{cm}^{3} \mathrm{~min}^{-1}$ over 20-40 min. Experimental samples were collected at $1.8-5.5 \mathrm{~cm}^{3} \mathrm{~min}^{-1}$ using peristaltic pumps (Cole-Parmer); flow rates varied by $<1 \%$ based on measurements throughout the study. For cleaning product experiments, integrated samples were resolved at least to the following schedule: 0-10, 10-30, and 30-60 min; and 1-2, 2-4, and 4-24 h from the start of the experiment. Sampling periods were further subdivided as needed to achieve sample masses within quantitation ranges. Samples were collected in duplicate, and pairs were analyzed for at least 1-2 periods of each experiment. For the air-freshener experiment, samples of 2-5 min duration were collected at intervals over three days beginning with the start of use.

Samples were analyzed by thermal desorption gas chromatography with mass selective detection and quantitation (TD-GC/MS) as described previously (Singer et al., 2004). Samples were analyzed on the day of collection or stored in a freezer for up to a few days before analysis. Most analytes were quantified using multipoint calibration curves developed from pure compounds (Aldrich). Quantitation was referenced to an internal standard of 1-bromo-4fluorobenzene. Analytes for which standards could not be obtained were identified using spectral libraries and quantified by total ion current, based on the instrument response to d-limonene.

\subsection{Emission factors}

Effective emission factors (i.e., mg of constituent emitted per g of total product used) were determined for major analytes by material-balance analysis. The key concept is that the effective net mass emitted into air is ultimately balanced by the mass removed from the chamber by means of ventilation. Since the chamber was continuously well mixed, the removal rate is determined as the time-integral of the product of the background-corrected chamber air concentration $\left(\mu \mathrm{g} \mathrm{m}^{-3}\right)$ times the ventilation rate $\left(\mathrm{m}^{3} \mathrm{~min}^{-1}\right)$. For the cleaning-product experiments (A-Q), mass emissions were determined using time-averaged concentration data for a 24 -h period beginning 
with product use. Mass emissions so determined were normalized to the quantity of product dispensed. Fractional emissions of analytes (i.e., g emitted per g dispensed) also were computed, utilizing the composition data. For the air freshener experiment (R), time-average analyte concentrations were estimated for the three days of product deployment using linear interpolation between points; these results were used to determine effective emission rates in units of mg $\mathrm{d}^{-1}$.

Emission factors are termed "effective" as they reflect the net result of emissions and material interactions including emissions from paper towels, desorption from cleaned surfaces, and net sorptive uptake to other chamber surfaces such as wallboard.

\section{RESULTS AND DISCUSSION}

\subsection{Product composition}

Product composition results are presented in Tables 3-5. Four of the five cleaning products contained 2-BE at mass concentrations of 6-62 $\mathrm{mg} \mathrm{mL}^{-1}$. The highest concentration of 2-BE was in GPC-3, which is a "concentrated” product sold in both trigger spray and screw-top bottles. Anecdotal reports of survey subjects suggest that the product often is used at full-strength to clean hard surfaces. The glass/surface cleaner contained both 2-BE and 2-hexyloxyethanol (2HE, CAS No. 112-25-4, also known as ethylene glycol monohexyl ether) at concentrations of 6 and $4 \mathrm{mg} \mathrm{mL}^{-1}$, respectively. GPC-4, marketed as a degreaser and cleaner and sold in a trigger spray bottle, contained both 2-BE and d-limonene at levels of 31 and $44 \mathrm{mg} \mathrm{mL}^{-1}$, respectively.

GPC-1 is a pine-oil based cleaner that contains 11 terpenoids including both terpene hydrocarbons and alcohols (plus at least two additional VOCs) at mass concentrations exceeding $1 \mathrm{mg} \mathrm{mL}^{-1}$ (Table 4). Several of these identified constituents are known to react rapidly with ozone. The reaction between d-limonene and ozone to form secondary pollutants has been well documented (see Nazaroff and Weschler, 2004, and references therein). Terpinolene has an ozone reaction rate that is roughly an order of magnitude higher than that of d-limonene (ibid) and is present in GPC- 1 at a higher mass fraction. $\alpha$-Terpinene is present at a much lower mass fraction but reacts with ozone about two orders of magnitude faster than does d-limonene (ibid). $\alpha$-Terpineol, which comprises almost 7\% of GPC-1, reacts with ozone at a rate comparable to that of d-limonene (Wells, 2005).

The air freshener contained six unsaturated and several saturated VOCs at levels above $6 \mathrm{mg}$ $\mathrm{mL}^{-1}$ (Table 5). Linalool reacts with ozone about twice as fast as does d-limonene (Nazaroff and Weschler, 2004).

\subsection{Product use rates}

Product use rates were determined based on 25 subjects using the spray cleaner and 11 subjects using the disinfectants. In each survey, use rates were reasonably fit by a lognormal distribution. The calculated geometric means (GM) and geometric standard deviations (GSD) of the distributions were $5.7 \mathrm{~g} \mathrm{~m}^{-2}$ and 1.9 for the trigger spray cleaner (GPC-3) and $6.4 \mathrm{~g} \mathrm{~m}^{-2}$ and 2.6 for the liquid cleaner and disinfectant (GPC-1). To obtain high but realistic product use rates, 
we chose levels corresponding to the measured GM $\times$ GSD, yielding application rates of 11 and $17 \mathrm{~g} \mathrm{~m}^{-2}$ ( 1 and $1.6 \mathrm{~g} \mathrm{ft}^{-2}$ ) for the trigger spray and liquid cleaner/disinfectant, respectively.

\subsection{Constituent gas-phase concentrations associated with product use}

Selected results for chamber air concentrations measured during product use are presented in Tables 5-7 and Figures 1-4. Broadly, these show that concentrations of ethylene-based glycol ethers, terpenes and related unsaturated compounds can reach levels as high as several hundred to several thousand $\mu \mathrm{g} \mathrm{m}^{-3}$ under both full-strength and dilute solution use. Six unsaturated compounds were measured at time-averaged concentrations in the range 7-160 $\mu \mathrm{g} \mathrm{m}^{-3}$ when the scented-oil air freshener was used. Background concentrations varied but were below $10 \mu \mathrm{g} \mathrm{m}^{-3}$ for all but the following cases: 2-BE in experiments $\mathrm{H}, \mathrm{K}, \mathrm{O}-\mathrm{P}\left(14-20 \mu \mathrm{g} \mathrm{m}^{-3}\right)$; limonene in

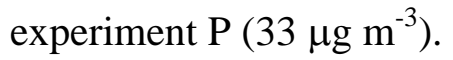

Representative data portraying time-dependent concentration patterns are shown in Figures 1-4. 2-Butoxyethanol concentration profiles varied across applications (Figures 1-2). Peak concentrations coincided with product use during full-strength counter cleaning with scrub and rinse (Figure 1, top). In contrast, peak concentrations were delayed until the second 30-min sampling interval during the dilute solution floor mopping experiments. The retention of towels in the chamber following counter cleaning led to elevated concentrations during later sampling periods (2-4 h and 4-24 h, top of Figure 1). The higher concentrations during the 4-24 h period had a substantial impact on effective emission factors (35-100\% increase), as can be seen by comparing experiments E-K with the corresponding experiments B-D (Table 6). Figure 2 shows that the spray and wipe application (towels retained) resulted in levels of 2-BE that exceeded 200 $\mu \mathrm{g} \mathrm{m}{ }^{-3}$ and $800 \mu \mathrm{g} \mathrm{m}^{-3}$ for $4 \mathrm{~h}$ following the cleaning events in Experiments $\mathrm{L}$ and $\mathrm{M}$, respectively.

Figure 2 includes idealized concentration profiles, which were computed assuming instantaneous emission at the start of cleaning (rather than persistent emissions during and following cleaning) and dynamic behavior of 2-BE corresponding to an inert tracer (e.g., no sorption). For each "idealized" trace, the mass emitted at time $\mathrm{t}=0$ is assumed to match the value calculated for 0-24 h based on the measured concentration profile. The idealized model corresponds closely to the measured profile for Experiment A, in which GLC-1 was applied full strength and towels were removed from the chamber. Idealized plots differ markedly from profiles measured in Experiments $\mathrm{L}$ and $\mathrm{M}$, which included no scrub or rinse steps. The deviations suggest that extended emission of 2-BE occurred over a period of $\sim 2-4 \mathrm{~h}$ owing to the continuing presence of used paper towels in the chamber.

Figure 3 shows substantial differences in the temporal concentration profiles of terpene as compared with a terpene alcohol, with the alcohol persisting at elevated concentrations 4-24 $\mathrm{h}$ after the cleaning event. The left-hand frames in this figure show that retention of towels in the chamber led to higher concentrations notably during the 2-4 h sampling period for terpenes and throughout the entire experiment for $\alpha$-terpineol. The lower right-hand frame shows that - as with 2-BE - the peak $\alpha$-terpineol concentration was delayed until the second 30-min period in the floor-mopping experiment. 
The panels on the right side of Figure 3 compare measured and idealized profiles for mopping with a dilute solution of GPC-1. The overall behavior of d-limonene and terpinolene is reasonably well predicted by the idealized model, whereas $\alpha$-terpineol deviates markedly. These observations are consistent with the expectation that, compared with terpene hydrocarbons, terpene alcohols will preferentially remain in aqueous solution or associate with surface-bound water leading to delayed release.

Sorption of gas-phase analytes to chamber surfaces may also contribute to the persistence of elevated concentrations and differences between measured and idealized profiles. An initial sorptive uptake rate constant of $0.32 \mathrm{~h}^{-1}$ has been reported for d-limonene in a furnished experimental chamber (Singer et al., 2004), and values of $1.5 \pm 0.5 \mathrm{~h}^{-1}$ (2-BE) and $2.7 \pm 1.0 \mathrm{~h}^{-1}$ (2$\mathrm{HE}$ ) have been determined for glycol ethers in residential bedrooms and bathrooms (Singer et al., 2005). Unpublished experiments indicate that initial adsorption in the unfurnished room used for this study occurs at roughly one-third to one-half of the rate reported for glycol ethers in residential rooms. Sorption was likely competitive with air exchange in the experiments reported herein, and, if so, would have affected the time-dependent concentration profiles.

Concentrations of air-freshener constituents varied over the 3-day experiment as shown in Figure 4. For d-limonene, dihydromyrcenol, and linalool, the temporal variability in concentrations correlates well with the measured changes in overall product volatilization rate. On the other hand, linalyl acetate and especially $\beta$-citronellol concentrations increased with time during the first half of the experiment, even though the overall product volatilization rate was declining. This divergence may result from varying volatilization and/or sorption behavior among the constituents.

Owing to the selection of appropriately scaled ratios of cleaned surface to air volume, along with realistic air-exchange and product usage rates, the absolute concentrations observed in the chamber experiments are expected to be relevant to those that would occur in residences, with the caveat that sorption is likely to play a more significant role in real indoor environments. To illustrate, consider a residence with a floor area of $170 \mathrm{~m}^{2}\left(1830 \mathrm{ft}^{2}\right)$ and volume of $375 \mathrm{~m}^{3}$, typical of US single-family dwellings (Nazaroff and Singer, 2004). In this residence, cleaning of $30 \mathrm{~m}^{2}$ of floor or $3.8 \mathrm{~m}^{2}$ of hard surfaces - consistent with comprehensive cleaning of kitchen or bathroom surfaces and floors - would achieve the same cleaned surface area to volume ratio as in the present experiments.

The potential for exposures at a level that would raise health concerns also can be evaluated through modeling of cleaning scenarios. Emission factors presented in Tables 6-7 can be combined with information on product application rate ( $\mathrm{g} \mathrm{m}^{-2}$ of cleaned surface), cleaning surface area, mixing volume (i.e., of the room or residence in which the product is used), airexchange rate, sorption rates and occupancy patterns to estimate inhalation exposure. For example, consider comprehensive cleaning in a $100 \mathrm{~m}^{3}$ efficiency apartment ventilated at $0.5 \mathrm{~h}^{-1}$. Assume that GPC-2 is used to clean $4 \mathrm{~m}^{2}$ of hard surfaces and that GPC-3 is used to mop $8 \mathrm{~m}^{2}$ of exposed flooring in the kitchen and bath areas. For the purposes of this example, assume initially that sorption of glycol ethers occurs at the same rate as in the experimental room. If the products 
are applied at the same rate as used in our study, peak 1-h 2-BE concentrations would be $\sim 7 \mathrm{mg}$ $\mathrm{m}^{-3}$; if products are applied at twice that rate, 1-h concentrations would reach California's acute REL for 2-BE. Use of products such as these in a closed bathroom, e.g. with a cleaning surface to volume ratio that could be an order of magnitude higher than those used in our study, likewise could lead to peak 1-h concentrations near or above the acute REL. Accounting for glycol ether adsorption at rates observed in real residential rooms (Singer et al., 2005) would reduce the estimated 1-h peak concentrations. Nevertheless, these calculations suggest that a more detailed investigation of 2-BE exposure owing to cleaning product use is warranted.

\subsection{Emissions associated with product use}

Emission rates and emission factors associated with product use are presented in Tables 5-7. These emission factors reflect the mass of each analyte measured in air and thus are relevant for estimating inhalation exposure over a 24-h period for the use of cleaning products and for the initial days of plug-in air freshener use. Emission rates $\left(\mathrm{mg} \mathrm{d}^{-1}\right)$ for individual unsaturated compounds associated with use of AFR-1 are provided in Table 5. For the cleaning products, emission factors are presented in Tables 6 and 7 as mass ratios (mg VOC emitted per g product used); these can be multiplied by product application rate $\left(\mathrm{g} \mathrm{m}^{-2}\right)$ and surface area cleaned $\left(\mathrm{m}^{2}\right)$ to estimate VOC emissions for a cleaning activity.

Figure 5 displays fractional emissions of d-limonene and 2-BE associated with various cleaning products and protocols. The emitted fraction varies strongly with application protocol: emission rates were highest for full-strength counter cleaning with towels retained and lowest for mopping with a dilute solution. Full-strength product use that entailed scrubbing and rinsing with a wetted sponge followed by wiping with paper towels produced fractional emissions in the range $\sim 50-70 \%$ when towels were retained in the chamber (experiments $\mathrm{E}-\mathrm{K}$ ) and $\sim 25-50 \%$ when towels were removed. The difference between these two groups of experiments is consistent with the expectation that some of the volatile constituents were retained in the water used during scrub and rinse procedures, and some was bound in the paper towels used in cleanup. In experiments $\mathrm{L}$ and $\mathrm{M}$, computed fractional emissions of 2-BE were very high, exceeding $100 \%$ based on the mean composition values. Note that there is significant uncertainty in the 2BE composition of individual cleaning products (see Table 3).

The low fractional emissions associated with mopping (2\% for 2-BE and $7-11 \%$ for $\mathrm{d}$ limonene) are not unexpected, since most of the cleaning solution remained in the bucket and was removed from the chamber at the conclusion of cleaning. About $8-10 \%$ of the solution was applied to the floor during the wet mop stage and about 2-3\% remained in the chamber after dry mopping. These data suggest that during the wet mop stage, when excess cleaning solution was applied to the floor, a substantial fraction of the d-limonene in that solution volatilized before the solution was collected during the dry mop stage. In contrast, the 2\% fractional emissions of 2$\mathrm{BE}$ are consistent with the net amount of solution dispensed, suggesting little volatilization from the excess solution applied during the wet mop stage.

Fractional emissions of terpenes and terpene alcohols from GPC-1 are presented in Figure 6. Consistent with results for other products, the emitted fraction of dispensed product was highest 
for full-strength product use with towel retention, lower for full-strength use with towel removal, and lowest for the dilute floor-mopping application. In addition to this dependence on application method, a dichotomy is apparent between the terpene hydrocarbons and terpene alcohols. In the floor-mopping scenario, fractional emissions of terpene alcohols were in the range of 2-5\% whereas terpene emissions were in the range of $7-12 \%$. The discrepancy was even larger for fullstrength counter cleaning: 2-9\% for the alcohols versus 20-50\% for the terpenes with towel removal, and $7-30 \%$ for the alcohols versus $35-70 \%$ for the terpenes with paper towels retained. Factors likely influencing these results include slower volatilization of the alcohols during initial application and greater partitioning of alcohols into the water during scrub and rinse procedures.

\subsection{Experimental uncertainty, variability, and bias}

Several sources of uncertainty, variability and bias associated with the experimental results were assessed. Uncertainty associated with the quantitation of individual VOC concentrations during a sampling interval was evaluated by analysis of results from duplicate samples, including $\mathrm{n}=28$ pairs for 2-BE, $\mathrm{n}=5$ for 2-HE, $\mathrm{n}=15$ for limonene, $\mathrm{n}=7$ for terpenes and terpene alcohols in GPC-1 and $\mathrm{n}=2$ for unsaturated compounds specific to AFR-1. Mean relative deviations were generally less than 5-8\%, excepting $\alpha$-terpinene (22\%), terpinolene (16\%), $\gamma$ terpineol (17\%), and $\alpha$-phellandrene (13\%). Imprecision in the amount of product used was \pm 0.1 g. Replicate counter-cleaning experiments with GPC-3 (F-H, Table 6) and GPC-4 (I-K, Table 6) informs variability associated with implementation of experimental protocols, and indicates good precision. Variability in the product composition measurements is presented in Tables 3-5. Variability in air-exchange rate during the course of an experiment was determined to be $<5 \%$ based on successive tracer-decay measurements. The effect of sorption and desorption processes represents another source of uncertainty and potential bias. Some emitted product constituents, including glycol ethers and terpene alcohols, likely sorbed during experiments. Any product constituent that remained sorbed to chamber material surfaces at the end of the $24 \mathrm{~h}$ experiment is not included in the calculated emission factors. Uncertainty in calculated emission factors associated with longer-term desorption was estimated to be $\sim 2 \%$ for experiments $\mathrm{L}$ and $\mathrm{P}$ and much less for other experiments.

\section{CONCLUSION}

This work contributes to efforts to better understand human exposures to primary and secondary pollutants associated with cleaning product use. Results provide information that is directly relevant to emissions and resulting gas-phase concentrations of glycol ethers (primary pollutants) and terpenes that react with ozone to form secondary pollutants. Simplified modeling of cleaning scenarios using the emission factors determined in this study indicates that peak 1-h exposure concentrations for 2-butoxyethanol might approach or potentially exceed California's acute reference exposure level of $14 \mathrm{mg} \mathrm{m}^{-3}$ in some situations. Limonene and other ozonereactive terpenoids present in cleaning products can reach $\mathrm{mg} \mathrm{m}^{-3}$ levels in air and persist at levels of tens to hundreds of $\mu \mathrm{g} \mathrm{m}^{-3}$ for many hours after cleaning. Air fresheners can produce steady-state levels of tens to hundreds of $\mu \mathrm{g} \mathrm{m}^{-3}$ of ozone-reactive terpenoids. Use of cleaning 
products and air fresheners in the presence of elevated indoor ozone is of concern because of the formation of secondary air pollutants that pose health risks.

\section{ACKNOWLEDGEMENTS}

The authors gratefully acknowledge the experimental contributions of De-Ling Liu, Tosh Hotchi and Michal Landau. We thank Charles Weschler and Dorothy Shimer (with colleagues from CARB) for their comments on the draft manuscript.

This work was funded by the California Air Resources Board Contract No. 01-336. The statements and conclusions in this report are those of the researchers and not necessarily those of the California ARB. The mention of commercial products, their source, or their use in connection with material reported herein in not to be construed as actual or implied endorsement of such products. All work at LBNL was conducted under US DOE Contract No. DE-AC02$05 \mathrm{CH} 11231$.

\section{REFERENCES}

Destaillats, H., Singer, B.C., Coleman, B.K., Lunden, M.M., Hodgson, A.T., Weschler, C.J., Nazaroff, W.W., 2005. Secondary pollutants from cleaning products and air fresheners in the presence of ozone. Proceedings of Indoor Air 2005, The 10th International Conference on Indoor Air Quality and Climate, Beijing, China. Also available as report LBNL-57038, Lawrence Berkeley National Laboratory, Berkeley, CA.

Fan, Z., Lioy, P., Weschler, C., Fiedler, N., Kipen, H., Zhang, J., 2003. Ozone-initiated reactions with mixtures of volatile organic compounds under simulated indoor conditions.

Environmental Science \& Technology 37, 1811-1821.

Gibson, W.B., Keller, P.R., Foltz, D.J., Harvey, G.J., 1991. Diethylene glycol mono butyl ether concentrations in room air from application of cleaner formulations to hard surfaces. Journal of Exposure Analysis and Environmental Epidemiology 1, 369-383.

Klenø, J., Wolkoff, P., 2004. Changes in eye blink frequency as a measure of trigeminal stimulation by exposure to limonene oxidation products, isoprene oxidation products and nitrate radicals. International Archives of Occupational and Environmental Health 77, 235243.

Li, T.-H., Turpin, B.J., Shields, H.C., Weschler, C.J., 2002. Indoor hydrogen peroxide derived from ozone/d-limonene reactions. Environmental Science \& Technology 36, 3295-3302.

Liu, X.Y., Mason, M., Krebs, K., Sparks, L., 2004. Full-scale chamber investigation and simulation of air freshener emissions in the presence of ozone. Environmental Science \& Technology 38, 2802-2812.

Nazaroff, W.W., Singer, B.C., 2004. Inhalation of hazardous air pollutants from environmental tobacco smoke in US residences. Journal of Exposure Analysis and Environmental Epidemiology 14, S71-S77.

Nazaroff, W.W., Weschler, C.J., 2004. Cleaning products and air fresheners: Exposure to primary and secondary air pollutants. Atmospheric Environment 38, 2841-2865. 
OEHHA, 1999. Determination of acute reference exposure levels for airborne toxicants. Air Toxicology and Epidemiology Section, California Office of Environmental Health Hazard Assessment, March, 1999. (http://www.oehha.ca.gov/air/acute_rels/allAcRELs.html).

Sarwar, G., Olson, D.A., Corsi R.L., Weschler, C.J., 2004. Indoor fine particles: The role of terpene emissions from consumer products. Journal of the Air \& Waste Management Association 54, 367-377.

Singer, B.C., Revzan, K.L., Hotchi, T., Hodgson, A.T., Brown, N.J., 2004. Sorption of organic gases in a furnished room. Atmospheric Environment 38, 2483-2494.

Singer, B.C., Hodgson, A.T., Hotchi, T., Ming, K.Y., Sextro, R.G., Wood, E.E., Brown, N.J., 2005. Sorption of organic gases in residential bedrooms and bathrooms. Proceedings of Indoor Air 2005, The 10th International Conference on Indoor Air Quality and Climate, Beijing, China. Also available as report LBNL-56787, Lawrence Berkeley National Laboratory, Berkeley, CA.

USEPA, 2003. List of hazardous air pollutants, petition process, lesser quantity designations, source category list. Federal Register 68 (225), 65648-65663, 21 November.

USEPA, 2004. List of hazardous air pollutants, petition process, lesser quantity designations, source category list; petition to delist of ethylene glycol monobutyl ether. Federal Register 69 (228), 69320-69325, 29 November.

Wainman, T., Zhang, J.F., Weschler, C.J., Lioy, P.J., 2000. Ozone and limonene in indoor air: A source of submicron particle exposure. Environmental Health Perspectives 108, 1139-1145.

Wells, J.R., 2005. Gas-phase chemistry of $\alpha$-terpineol with ozone and OH radical: Rate constants and products. Environmental Science \& Technology 39, 6937-6943.

Weschler, C.J., Shields, H.C., 1997. Measurements of the hydroxyl radical in a manipulated but realistic indoor environment. Environmental Science \& Technology 31, 3719-3722.

Weschler, C.J., Shields, H.C., 1999. Indoor ozone/terpene reactions as a source of indoor particles. Atmospheric Environment 33, 2301-2312.

Wolkoff, P., Clausen, P.A., Wilkins, C.K., Nielsen, G.D., 2000. Formation of strong airway irritants in terpene/ozone mixtures. Indoor Air 10, 82-91.

Wolkoff, P., Schneider, T., Kildesø, J., Degerth, R., Jaroszewski, M., Schunk, H., 1998. Risk in cleaning: Chemical and physical exposure. The Science of the Total Environment 215, 135156.

Zhu, J., Cao, X.L., Beauchamp, R., 2001. Determination of 2-BE emissions from selected consumer products and its application in assessment of inhalation exposure associated with cleaning tasks. Environment International 26, 589-597. 
Table 1. Summary information for six products.

\begin{tabular}{|c|c|c|c|}
\hline Product & $\begin{array}{l}\text { Constituents of } \\
\text { interest }\end{array}$ & $\begin{array}{l}\text { Package } \\
\text { form }\end{array}$ & $\begin{array}{l}\text { Recommended uses (selected from packaging), } \\
\text { directions, and dilutions in water. }^{\text {a }}\end{array}$ \\
\hline GLC-1 & $\begin{array}{l}\text { 2-butoxyethanol, } \\
\text { 2-hexyloxyethanol }\end{array}$ & $\begin{array}{l}\text { trigger } \\
\text { spray }\end{array}$ & $\begin{array}{l}\text { Glass, plastic, enamel, tile, porcelain; appliances, } \\
\text { stovetops, counters, cabinets, vanities, windows. } \\
\text { Spray directly onto surface, wipe dry with towel. }\end{array}$ \\
\hline GPC-1 & $\begin{array}{l}\text { terpenes, } \\
\text { terpene alcohols } \\
\text { (pine oil) }\end{array}$ & $\begin{array}{l}\text { capped } \\
\text { bottle }\end{array}$ & $\begin{array}{l}\text { Hard, non-porous household surfaces (counters, } \\
\text { sinks, stoves, showers, tile, floors, toilet, etc.). } \\
\text { 1/4 cup/gal: general cleaning. FS for tough jobs. } \\
\text { Disinfection: wipe FS onto surface, let stand } 5 \\
\text { min, remove excess. }\end{array}$ \\
\hline GPC-2 & 2-butoxyethanol & $\begin{array}{l}\text { trigger } \\
\text { spray }\end{array}$ & $\begin{array}{l}\text { Kitchen grease, bathroom soils, household. Spray } \\
\text { straight onto soils, wipe clean with a dry paper } \\
\text { towel or cloth. Repeat for heavily soiled areas. }\end{array}$ \\
\hline GPC-3 & 2-butoxyethanol & $\begin{array}{l}\text { trigger } \\
\text { spray }\end{array}$ & $\begin{array}{l}\text { FS: Ovens, grills, range hoods, vents, etc. } \\
\text { 1:10: Counters, stove-tops, refrigerators, sinks, } \\
\text { showers, tubs, tile, toilets, etc. } \\
\text { 1:30: Floors (vinyl, tile, wood), painted surfaces, } \\
\text { chrome, plastic, cabinets, blinds, carpets/fabrics. }\end{array}$ \\
\hline GPC-4 & $\begin{array}{l}\text { 2-butoxyethanol, } \\
\text { d-limonene }\end{array}$ & $\begin{array}{l}\text { trigger } \\
\text { spray }\end{array}$ & $\begin{array}{l}\text { 1:1: Appliances, countertops, sinks, ovens, } \\
\text { basins, tubs, showers, aluminum, ceramic tile. } \\
\text { 1:20: Cabinets, walls, floors \& painted surfaces. }\end{array}$ \\
\hline AFR-1 & $\begin{array}{l}\text { unsaturated } \\
\text { terpenoids } \\
\text { (scented oil) }\end{array}$ & $\begin{array}{l}\text { plug-in } \\
\text { heated } \\
\text { dispenser }\end{array}$ & $\begin{array}{l}\text { Dispenser volatilizes product constituents over } \\
\text { several weeks }\end{array}$ \\
\hline
\end{tabular}


Table 2. Summary of 18 simulated-use experiments conducted in $50 \mathrm{~m}^{3}$ chamber.

\begin{tabular}{lcccccc}
\hline Product & Expt & $\begin{array}{c}\text { Start Date } \\
(2003)\end{array}$ & $\begin{array}{c}\text { Product } \\
\text { used }(\mathrm{g})\end{array}$ & $\begin{array}{c}\mathrm{AER}^{\mathrm{a}} \\
\left(\mathrm{h}^{-1}\right)\end{array}$ & $\begin{array}{c}\mathrm{T}\left({ }^{\circ} \mathrm{C}\right) \\
\mu \pm \sigma\end{array}$ & $\begin{array}{c}\mathrm{RH}(\%) \\
\mu \pm \sigma\end{array}$ \\
\hline \multicolumn{7}{l}{ Counter cleaning } \\
GLC-1 & A & 23-Jul & 6.4 & $0.51^{\mathrm{b}}$ & $23.1 \pm 0.3$ & $51 \pm 1$ \\
GPC-1 & $\mathrm{B}$ & 25-Aug & 10 & $0.53^{\mathrm{b}}$ & $22.1 \pm 0.5$ & $59 \pm 2$ \\
GPC-3 & $\mathrm{C}$ & 31-Jul & 6.0 & $0.52^{\mathrm{b}}$ & $23.2 \pm 0.3$ & $63 \pm 1$ \\
GPC-4 & D & 01-Aug & 6.6 & 0.52 & $23.3 \pm 0.4$ & $62 \pm 1$
\end{tabular}

Counter cleaning with scrub and rinse, full strength product; towels retained

$\begin{array}{ccccccc}\text { GPC-1 } & \text { E } & \text { 28-Aug } & 9.9 & 0.53 & 22.0 \pm 0.2 & 58 \pm 1 \\ \text { GPC-3 } & \text { F } & \text { 04-Sep } & 6.0 & 0.53 & 21.9 \pm 0.4 & 63 \pm 1 \\ \text { GPC-3 } & \text { G } & \text { 10-Sep } & 6.0 & 0.51 & 21.9 \pm 0.4 & 60 \pm 6 \\ \text { GPC-3 } & \text { H } & \text { 30-Sep } & 5.9 & 0.52^{\text {b }} & 22.0 \pm 0.2 & 55 \pm 1 \\ \text { GPC-4 } & \text { I } & \text { 09-Sep } & 6.6 & 0.54 & 22.0 \pm 0.2 & 67 \pm 5 \\ \text { GPC-4 }^{\text {c }} & \text { J } & \text { 22-Dec } & 6.2 & 0.54 & \text { NA } & \text { NA } \\ \text { GPC-4 } & \text { K } & \text { 23-Dec } & 5.7 & 0.55 & 20.8 \pm 0.1 & 41 \pm 1\end{array}$

Counter cleaning, spray and wipe only, full strength product; towels retained
GLC-1
L $\quad$ 02-Sep
6.5
0.52
$22.1 \pm 0.2$
$66 \pm 2$
GPC-2
M 25-Sep
6.3
0.52
$21.9 \pm 0.0^{\mathrm{d}}$
$52 \pm 0^{\mathrm{d}}$

Floor mopping, product diluted in 1 gal $\mathrm{H}_{2} \mathrm{O}$; towels retained

$\begin{array}{lllrlll}\text { GPC-1 } & \mathrm{N} & \text { 18-Sep } & 50 & 0.51 & 21.9 \pm 0.4 & 35 \pm 3 \\ \text { GPC-3 } & \mathrm{O} & \text { 17-Sep } & 103 & 0.50 & 22.1 \pm 0.3 & 44 \pm 7 \\ \text { GPC-4 } & \mathrm{P} & \text { 16-Sep } & 53 & 0.55 & 22.0 \pm 0.2 & 51 \pm 2 \\ \text { GPC-4 } & \mathrm{Q} & \text { 29-Sep } & 153 & 0.52 & 21.9 \pm 0.3 & 54 \pm 3\end{array}$

Air freshener: plugged in and operated on highest of three settings

\begin{tabular}{lllllll} 
AFR-1 & $\mathrm{R}$ & $11-\mathrm{Sep}$ & $1.5 \mathrm{~g} / \mathrm{d}$ & 0.54 & $22.6 \pm 0.7$ & $45 \pm 5$ \\
\hline
\end{tabular}

${ }^{a}$ Air-exchange rates calculated from $\mathrm{SF}_{6}$ concentration decay.

${ }^{\mathrm{b}}$ Air-exchange measurement made on different day; air supply unaltered.

${ }^{\mathrm{c}}$ Experiment aborted due to problems with T/RH data; VOC data available for first $4 \mathrm{~h}$.

${ }^{\mathrm{d}}$ Temperature and relative humidity data available for first 7 hours only.

Table 3. Concentration ( $\mathrm{mg} \mathrm{mL}^{-1}$ ) of d-limonene and ethylene-based glycol ethers in five cleaning products determined by direct analysis of product diluted in methanol. ${ }^{\text {a }}$

\begin{tabular}{llcll}
\hline Product & $\mathrm{n}$ & $\mathrm{d}$-Limonene & 2-BE & 2-HE \\
\hline GLC-1 & 4 & - & $6.0 \pm 1.3$ & $3.7 \pm 1.5$ \\
GPC-1 & 3 & $14.7 \pm 1.5$ & - & - \\
GPC-2 & 5 & - & $26 \pm 4$ & - \\
GPC-3 & 7 & - & $62 \pm 10$ & - \\
GPC-4 & 4 & $44 \pm 5$ & $31 \pm 6$ & - \\
\hline
\end{tabular}

\footnotetext{
${ }^{a}$ Results presented as mean \pm one standard deviation, where $\mathrm{n}$ is number of diluted samples prepared; multiple injections from same dilution were averaged. 2-BE = 2-butoxyethanol; 2-HE = 2hexyloxyethanol.
} 
Table 4. Composition of GPC-1 determined by direct analysis of product diluted in methanol. ${ }^{\mathrm{a}}$

\begin{tabular}{|c|c|c|c|}
\hline Analyte $^{\mathrm{b}}$ & CAS \# & $\begin{array}{l}\mathrm{RT}^{\mathrm{C}} \\
(\mathrm{min})\end{array}$ & $\begin{array}{c}\text { Concentration } \\
\left(\mathrm{mg} \mathrm{mL}^{-1}\right)\end{array}$ \\
\hline \multicolumn{4}{|c|}{ Terpene hydrocarbons } \\
\hline$\alpha$-Pinene & $80-56-8$ & 21.8 & $1.1 \pm 0.6$ \\
\hline Camphene & $79-92-5$ & 22.8 & $1.2 \pm 0.1$ \\
\hline$\beta$-Pinene & $127-91-3$ & 24.0 & $0.13 \pm 0.01$ \\
\hline$\alpha$-Phellandrene ${ }^{\mathrm{d}}$ & $99-83-2$ & 25.1 & $0.42 \pm 0.13$ \\
\hline$\alpha$-Terpinene & $99-86-5$ & 25.6 & $2.5 \pm 0.7$ \\
\hline d-Limonene & $5989-27-5$ & 25.9 & $14.7 \pm 1.5$ \\
\hline$\gamma$-Terpinene & $99-85-4$ & 27.0 & $1.8 \pm 0.2$ \\
\hline Terpinolene & $586-62-9$ & 27.9 & \pm 3 \\
\hline \multicolumn{4}{|c|}{ Terpene alcohols } \\
\hline 1-Terpineol ${ }^{\mathrm{d}}$ & $586-82-3$ & 31.9 & $8.3 \pm 1.2$ \\
\hline$\beta$-Terpineol ${ }^{\mathrm{d}}$ & $138-87-4$ & 32.7 & $4.6 \pm 0.7$ \\
\hline 4-Terpineol ${ }^{\mathrm{d}}$ & $562-74-3$ & 33.1 & $3.0 \pm 0.4$ \\
\hline$\alpha$-Terpineol & $98-55-5$ & 34.0 & \pm 11 \\
\hline$\gamma$-Terpineol & $586-81-2$ & 34.2 & \pm 0.5 \\
\hline \multicolumn{4}{|c|}{ Other VOCs ${ }^{\mathrm{e}}$} \\
\hline p-Cymene & $99-87-6$ & 26.6 & $1.9 \pm 0.7$ \\
\hline Eucalyptol & $470-82-6$ & 26.7 & $4.1 \pm 0.1$ \\
\hline
\end{tabular}

\footnotetext{
${ }^{a}$ Results presented as mean \pm one standard deviation for $n=3$ dilution mixtures.

${ }^{\mathrm{b}}$ Compounds listed in retention-time order, except for "other VOCs”. Four additional compounds, tentatively identified as terpene hydrocarbons (3) and a terpineol isomer, were present at $<0.1 \%$. Identified analytes accounted for approximately $15 \%$ of the product mass.

${ }^{\mathrm{c}} \mathrm{GC} / \mathrm{MS}$ retention time; RT of internal standard (bromofluorobenzene) was $23.9 \mathrm{~min}$.

${ }^{\mathrm{d}}$ Quantified by total ion current based on d-limonene response. Identity of $\alpha$-phellandrene confirmed with pure standard; terpineols tentatively identified by matching mass spectra to NIST database. Uncertainty in TIC quantitation estimated as $\pm 30 \%$ or less. 4 -Terpineol may be biased high because of a potentially co-eluting compound.

e Selected VOCs; other compounds identified in product include 2-propanol, borneol, camphor, and isoborneol.
} 
Table 5. Composition, chamber air concentrations, and emission rates for terpenoids and other VOCs in scented-oil air freshener, AFR-1.

\begin{tabular}{|c|c|c|c|c|c|}
\hline Analyte & CAS \# & $\begin{array}{c}\mathrm{RT} \\
(\mathrm{min})\end{array}$ & $\begin{array}{l}\text { Composition } \\
\left(\mathrm{mg} \mathrm{mL}^{-1}\right)^{\mathrm{a}}\end{array}$ & $\begin{array}{c}\text { Concentration } \\
\left(\mu \mathrm{g} \mathrm{m}^{-3}\right)^{\mathrm{b}}\end{array}$ & $\begin{array}{l}\text { Emission rate } \\
\qquad\left(\mathrm{mg} \mathrm{d}^{-1}\right)^{\mathrm{c}}\end{array}$ \\
\hline \multicolumn{6}{|c|}{ Unsaturated (ozone-reactive) VOCs $^{\mathrm{d}}$} \\
\hline d-Limonene & $5989-27-5$ & 25.9 & 17 & 35 & 39 \\
\hline Dihydromyrcenol $^{\mathrm{e}}$ & $18479-58-8$ & 29.7 & 71 & 160 & 180 \\
\hline Linalool & $78-70-6$ & 30.6 & 65 & 132 & 148 \\
\hline Linalyl acetate ${ }^{\mathrm{e}}$ & $115-95-7$ & 34.5 & 25 & 56 & 63 \\
\hline$\beta$-Citronellol & $7540-51-4$ & 35.1 & 23 & 30 & 34 \\
\hline$\alpha$-Citral & $141-27-5$ & 37.0 & 6.2 & 6.8 & 7.7 \\
\hline \multicolumn{6}{|c|}{ Other VOCs ${ }^{\mathrm{f}}$} \\
\hline 3,7-Dimethyl-3-octanol ${ }^{\mathrm{e}}$ & $78-69-3$ & 30.2 & 40 & 87 & 98 \\
\hline Benzyl acetate & $140-11-4$ & 33.4 & 136 & 280 & 320 \\
\hline Bornyl acetate & $76-49-3$ & 36.3 & 47 & 410 & 460 \\
\hline
\end{tabular}

${ }^{\mathrm{a}}$ Composition determined by analysis of product diluted in methanol (mean of 2 determinations).

b Time-averaged concentration over first 3 days of use in chamber calculated by linear interpolation between sampling points. See also Figure 4.

${ }^{\mathrm{c}}$ Mean emission rate over first 3 days of use in large-chamber experiments.

${ }^{\mathrm{d}}$ In addition to the compounds shown, $\beta$-pinene was quantified at $\sim 1.5 \mathrm{mg} \mathrm{mL}^{-1}$ in composition experiments. Concentrations and calculated emissions during product-use experiments were consistent with this value; precise determination was precluded owing to high background levels.

${ }^{\mathrm{e}}$ Quantified by total ion current based on d-limonene response; uncertainty estimated as $\pm 30 \%$ or less. Compound identities confirmed with pure standards.

${ }^{\mathrm{f}}$ Selected prominent VOCs. Other constituents identified and quantified with pure standards include phenylethyl alcohol (RT=33.3 min, $\sim 50 \mathrm{mg} \mathrm{mL}^{-1}$ ) and trans-4-tert-butylcylcohexyl acetate (RT=38.5 min, $\sim 10 \mathrm{mg} \mathrm{mL}^{-1}$ ). Constituents tentatively identified by matching mass spectra to NIST database and quantified by TIC response include isononyl acetate (RT=32.0 min, $\sim 50 \mathrm{mg} \mathrm{mL}^{-1}$ ) and $\alpha, \alpha-$ dimethylbenzene ethanol acetate ( $\mathrm{RT}=37.5 \mathrm{~min}, \sim 6 \mathrm{mg} \mathrm{mL}^{-1}$ ). Positively and tentatively identified analytes together accounted for approximately $65 \%$ of the product mass. 
Table 6. Emission factors and initial chamber air concentrations for d-limonene and ethylenebased glycol ethers associated with simulated cleaning activities. ${ }^{\text {a }}$

\begin{tabular}{|c|c|c|c|c|c|c|c|}
\hline \multirow[b]{2}{*}{ Product } & \multirow[b]{2}{*}{ Expt } & \multicolumn{3}{|c|}{$\begin{array}{l}\text { Emission factor } \\
\text { (mg per g product) }\end{array}$} & \multicolumn{3}{|c|}{$\begin{array}{c}\text { Chamber air concentration } \\
0-1 \mathrm{~h}^{\left(\mu \mathrm{g} \mathrm{m}^{-3}\right)}\end{array}$} \\
\hline & & $\operatorname{Lim}$ & 2-BE & 2-HE & Lim & 2-BE & 2-HE \\
\hline \multicolumn{8}{|c|}{ Counter: full strength with scrub and rinse; towels removed } \\
\hline GLC-1 & A & - & 2.6 & 1.9 & - & 270 & 170 \\
\hline GPC-1 & B & 6.8 & - & - & 960 & - & - \\
\hline GPC-3 & $\mathrm{C}$ & - & 25 & - & - & 2300 & - \\
\hline GPC-4 & $\mathrm{D}$ & 22 & 7.4 & - & 2200 & 720 & - \\
\hline \multicolumn{8}{|c|}{ Counter: full-strength with scrub and rinse; towels retained } \\
\hline GPC-1 & $\mathrm{E}$ & 10.2 & - & - & 1100 & - & - \\
\hline GPC- $3^{b}$ & F-H & - & $34 \pm 1$ & - & - & $1600 \pm 80$ & - \\
\hline GPC- $4^{\mathrm{c}}$ & $\mathrm{I}-\mathrm{K}$ & 30,32 & 15,16 & - & $2500 \pm 70$ & $680 \pm 50$ & - \\
\hline \multicolumn{8}{|c|}{ Counter: full-strength, spray and wipe only; towels retained } \\
\hline GLC-1 & $\mathrm{L}$ & - & 8.0 & 4.8 & - & 330 & 190 \\
\hline GPC-2 & M & - & 30 & - & - & 1410 & - \\
\hline \multicolumn{8}{|c|}{ Floor mopping with dilute solution } \\
\hline GPC-1 & $\mathrm{N}$ & 1.6 & - & - & 1130 & - & - \\
\hline GPC-3 & $\mathrm{O}$ & - & 1.3 & - & - & 1300 & - \\
\hline GPC- $4^{d}$ & $\mathrm{P}$ & 3.7 & 0.7 & - & 2900 & 380 & - \\
\hline GPC-4 ${ }^{\mathrm{d}}$ & $\mathrm{Q}$ & 2.7 & 0.7 & - & 6200 & 1150 & - \\
\hline
\end{tabular}

\footnotetext{
${ }^{\mathrm{a}}$ Net 24-h emission factors and 1-h-average gas-phase concentrations beginning when cleaning commenced; Lim = d-limonene, 2-BE = 2-butoxyethanol, 2-HE = 2-hexyloxyethanol.

${ }^{\mathrm{b}}$ Results (mean \pm standard deviation) are from three experiments, $\mathrm{F}-\mathrm{H}$.

${ }^{\mathrm{c}}$ Results are from two experiments (I, K) in the case of emissions, and from three experiments (I-K) in the case of the first-hour average concentrations.

${ }^{\mathrm{d}}$ Experiments conducted with different product dilutions; see Table 2.
} 
Table 7. Emission factors and initial chamber air concentrations of terpenes and terpene alcohols associated with use of GPC- $1 .{ }^{\mathrm{a}}$

\begin{tabular}{|c|c|c|c|c|c|c|}
\hline \multirow[b]{2}{*}{ Analyte } & \multicolumn{3}{|c|}{$\begin{array}{l}\text { Emission factor } \\
\text { (mg per g product) }\end{array}$} & \multicolumn{3}{|c|}{$\begin{array}{l}\text { Chamber air concentration } \\
0-1 \mathrm{~h}\left(\mu \mathrm{g} \mathrm{m}^{-3}\right)\end{array}$} \\
\hline & $\begin{array}{l}\text { Exp B } \\
\text { Counter }\end{array}$ & $\begin{array}{c}\text { Exp E } \\
\text { Counter }\end{array}$ & $\begin{array}{l}\text { Exp N } \\
\text { Floor }\end{array}$ & $\begin{array}{c}\text { Exp B } \\
\text { Counter }\end{array}$ & $\begin{array}{c}\text { Exp E } \\
\text { Counter }\end{array}$ & $\begin{array}{l}\text { Exp N } \\
\text { Floor }\end{array}$ \\
\hline \multicolumn{7}{|c|}{ Terpene hydrocarbons } \\
\hline$\alpha$-Pinene & 0.41 & 0.56 & 0.09 & 58 & 74 & 66 \\
\hline Camphene & 0.61 & 0.84 & 0.14 & 87 & 109 & 105 \\
\hline$\beta$-Pinene & 0.09 & 0.06 & 0.01 & 12 & 14 & 13 \\
\hline$\alpha$-Phellandrene ${ }^{\mathrm{b}}$ & 0.14 & 0.24 & 0.04 & 23 & 29 & 29 \\
\hline$\alpha$-Terpinene & 0.49 & 0.89 & 0.16 & 90 & 113 & 124 \\
\hline d-Limonene & 6.8 & 10.2 & 1.6 & 960 & 1100 & 1130 \\
\hline$\gamma$-Terpinene & 0.66 & 1.15 & 0.17 & 95 & 112 & 120 \\
\hline Terpinolene & 5.5 & 10.3 & 1.8 & 890 & 1040 & 1270 \\
\hline \multicolumn{7}{|c|}{ Terpene alcohols } \\
\hline 1-Terpineol ${ }^{b}$ & 0.52 & 1.8 & 0.37 & 57 & 75 & 160 \\
\hline$\beta$-Terpineol ${ }^{b}$ & 0.30 & 0.85 & 0.18 & 39 & 41 & 75 \\
\hline 4-Terpineol ${ }^{\mathrm{b}}$ & 0.27 & 0.89 & 0.15 & 44 & 48 & 74 \\
\hline$\alpha$-Terpineol & 2.8 & 7.4 & 2.3 & 260 & 340 & 700 \\
\hline$\gamma$-Terpineol & 0.26 & 0.79 & 0.25 & 31 & 41 & 93 \\
\hline \multicolumn{7}{|c|}{ Other VOCs } \\
\hline p-Cymene & 1.04 & 1.63 & 0.25 & 142 & 172 & 174 \\
\hline Eucalyptol & 1.80 & 3.0 & 0.45 & 250 & 300 & 330 \\
\hline \multicolumn{7}{|c|}{$\begin{array}{l}\text { a Net 24-h emission factors and 1-h-average gas-phase concentrations beginning when cleaning } \\
\text { commenced. Experiments B and E simulated cleaning of laminate tabletop using full-strength product; } \\
\text { paper towels were removed after cleaning in experiment B and retained throughout in experiment E. In } \\
\text { experiment N, product was diluted in water and used to mop floor. }\end{array}$} \\
\hline \multicolumn{7}{|c|}{$\begin{array}{l}{ }^{\mathrm{b}} \text { Quantified by total ion current based on d-limonene response. Identity of } \alpha \text {-phellandrene confirmed with } \\
\text { pure standard; terpineols tentatively identified by matching mass spectra to NIST database. Uncertainty } \\
\text { in TIC quantitation estimated as } \pm 30 \% \text { or less. } 4 \text {-Terpineol may be biased high because of a potentially } \\
\text { co-eluting compound. }\end{array}$} \\
\hline
\end{tabular}




\section{FIGURE CAPTIONS}

Figure 1. Measured concentrations of 2-butoxyethanol following simulated use of GPC-3 and GPC-4 in selected large chamber experiments. (Data for times and masses indicate duration of cleaning activity and amount of cleaning product applied, respectively.)

Figure 2. Measured concentrations of 2-butoxyethanol following simulated use of GLC-1 (Experiments A \& L) and GPC-2 (Experiment M) in large chamber experiments, and with idealized theoretical time profiles. "Idealized” represents expectations for instantaneous release of an inert tracer into a well-mixed indoor air volume ventilated at a constant rate. Mass emitted, indoor volume, and ventilation rate for the idealized profile match measured conditions for these experiments.

Figure 3. Measured concentrations of major terpene and terpene-alcohol constituents following application of GPC-1 in large-chamber experiments. Right-hand panels compare measured results with idealized time profiles; see Figure 2 caption for additional information.

Figure 4. Results of experiment R, using scented-oil air freshener, indicating time-dependent concentrations of selected unsaturated organic compounds (various symbols as indicated, read against left-hand scales), and total rate of air freshener product volatilization (continuous line, read against right-hand scale). Air freshener operation commenced at time $=0$.

Figure 5. Emitted fraction of 2-butoxyethanol and d-limonene for cleaning-product experiments conducted in $50-\mathrm{m}^{3}$ chamber. Emitted fraction is defined as the mass of VOC emitted into the gas phase divided by the amount dispensed in connection with cleaning-product use.

Figure 6. Emitted fraction of terpenes and terpene alcohols associated with use of cleaning product GPC-1. Emitted fraction is defined as the mass of VOC emitted into the gas phase divided by the amount dispensed in connection with cleaning-product use. 

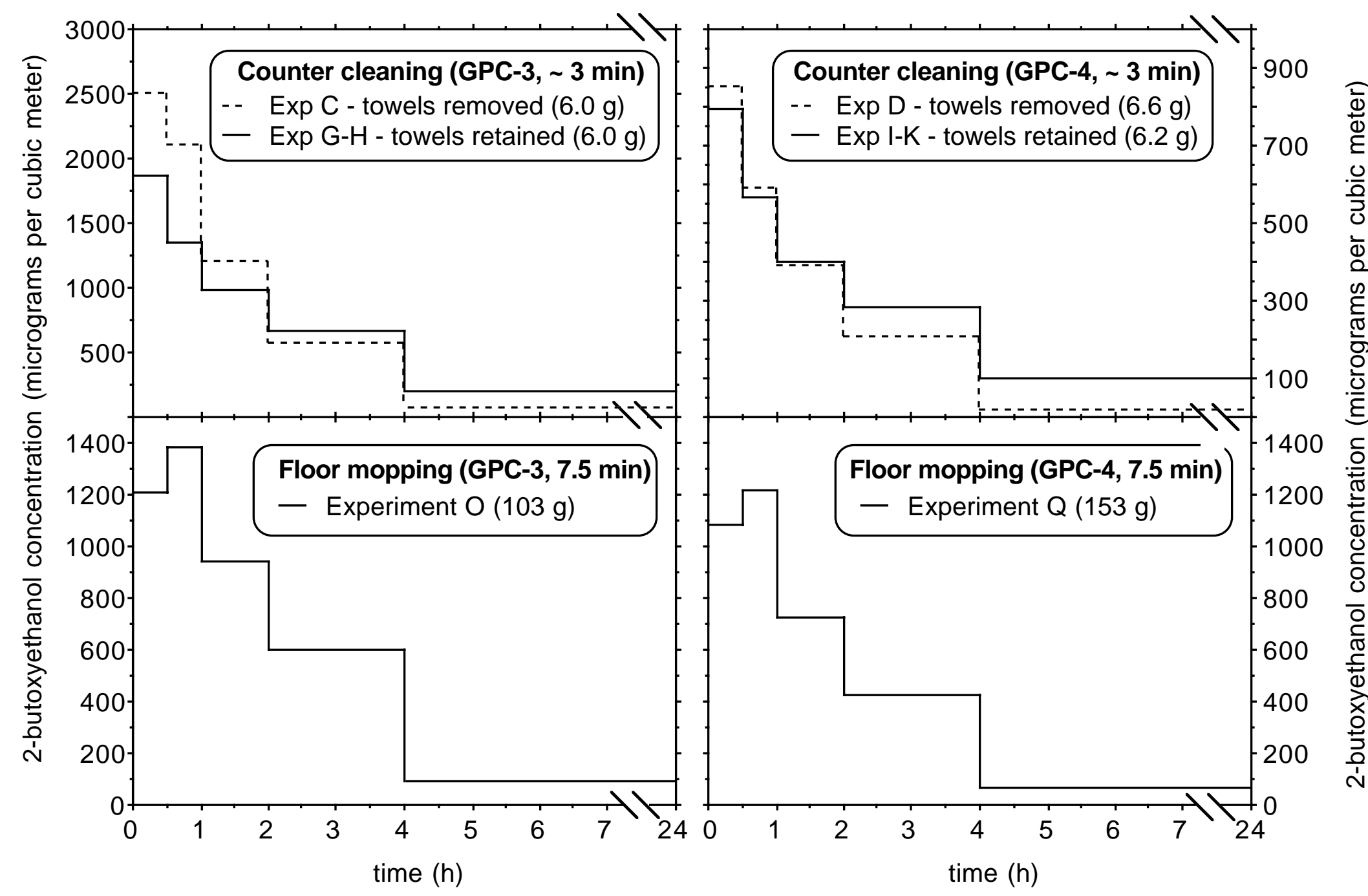


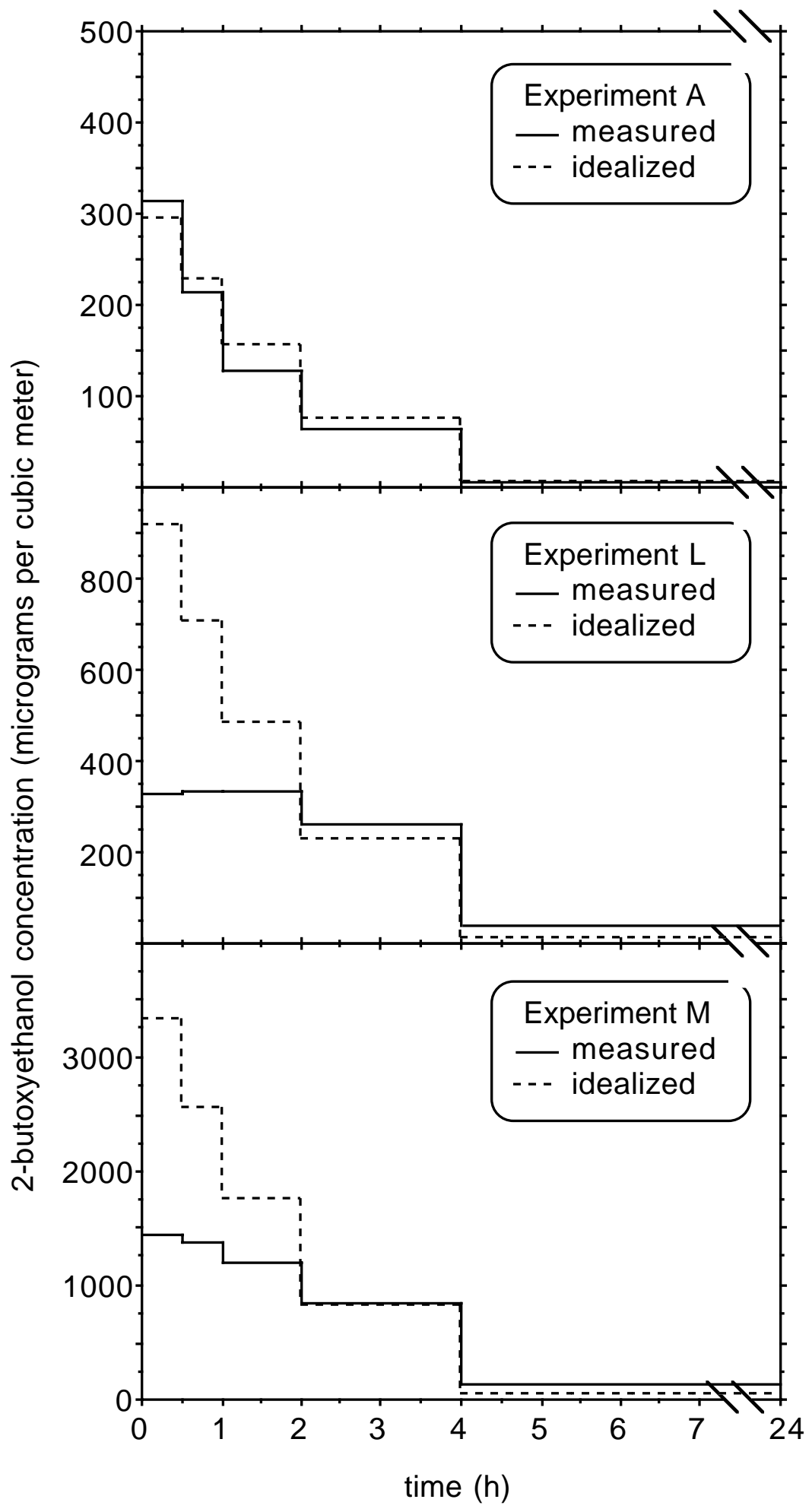




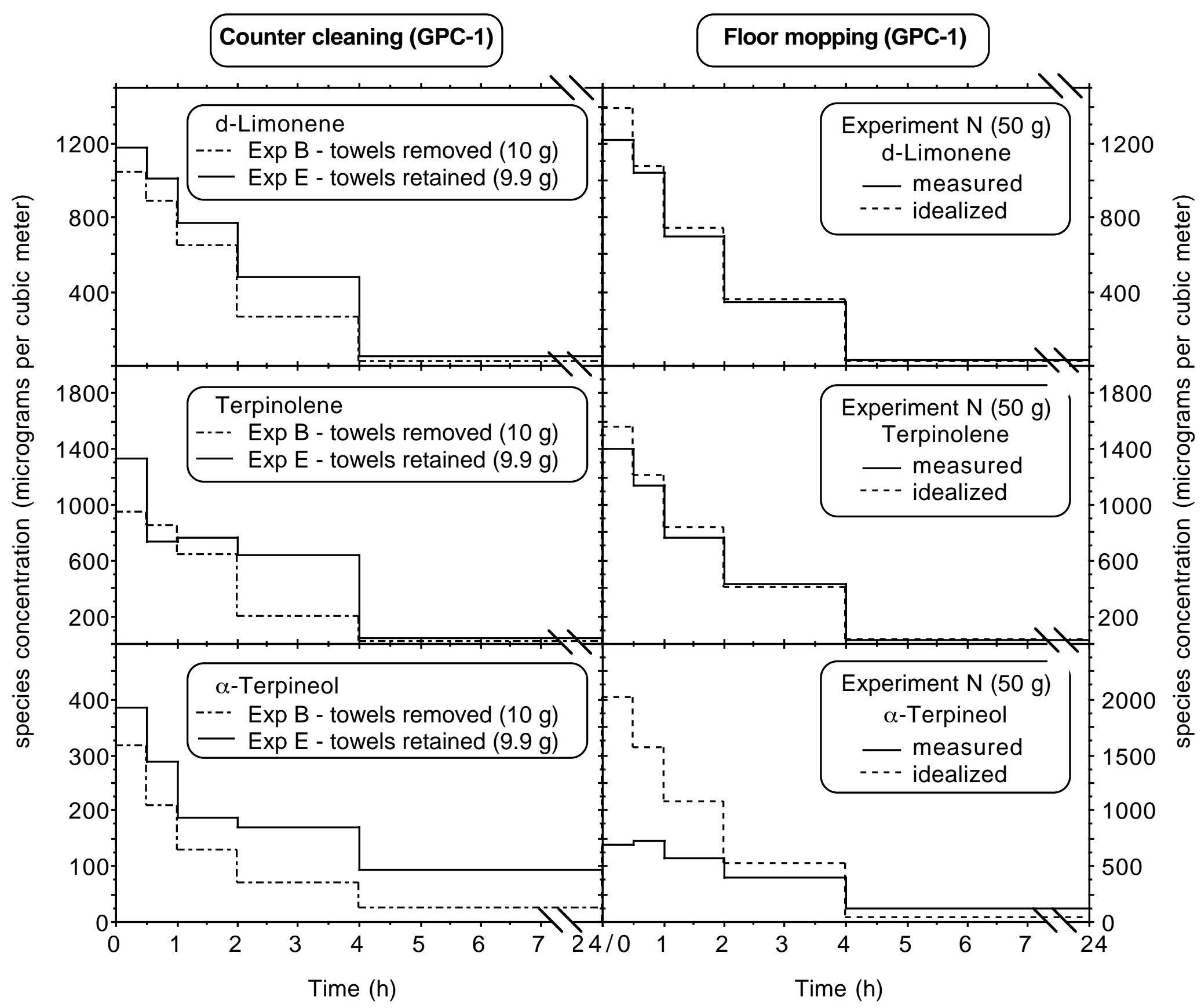




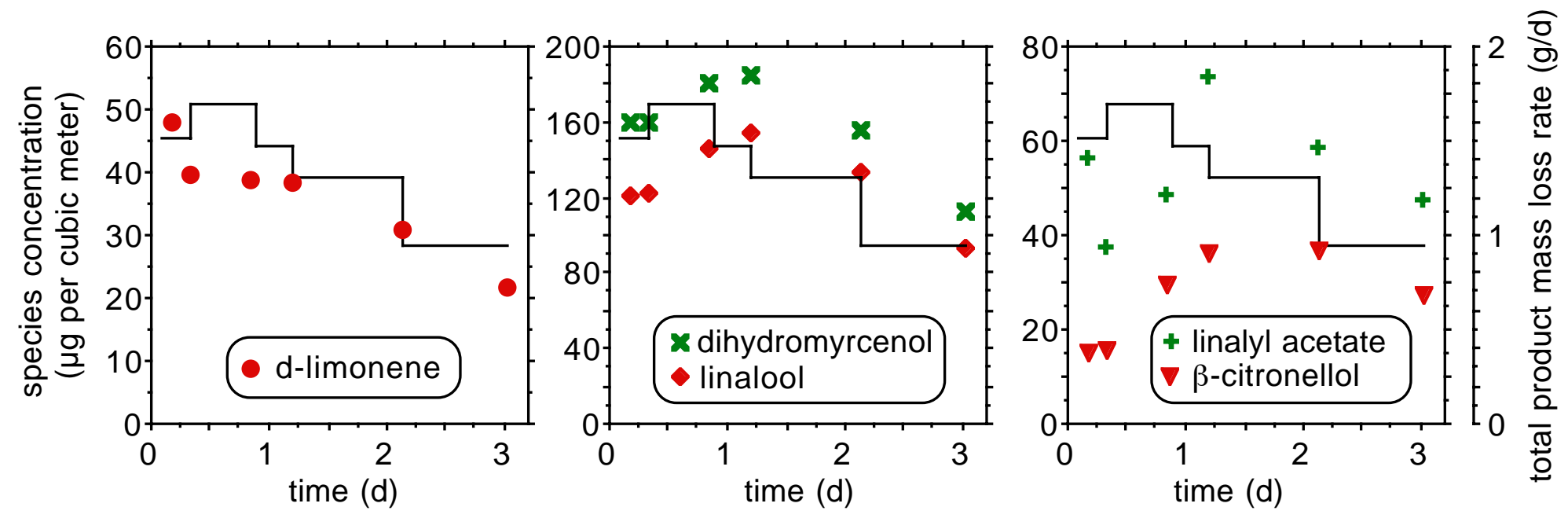




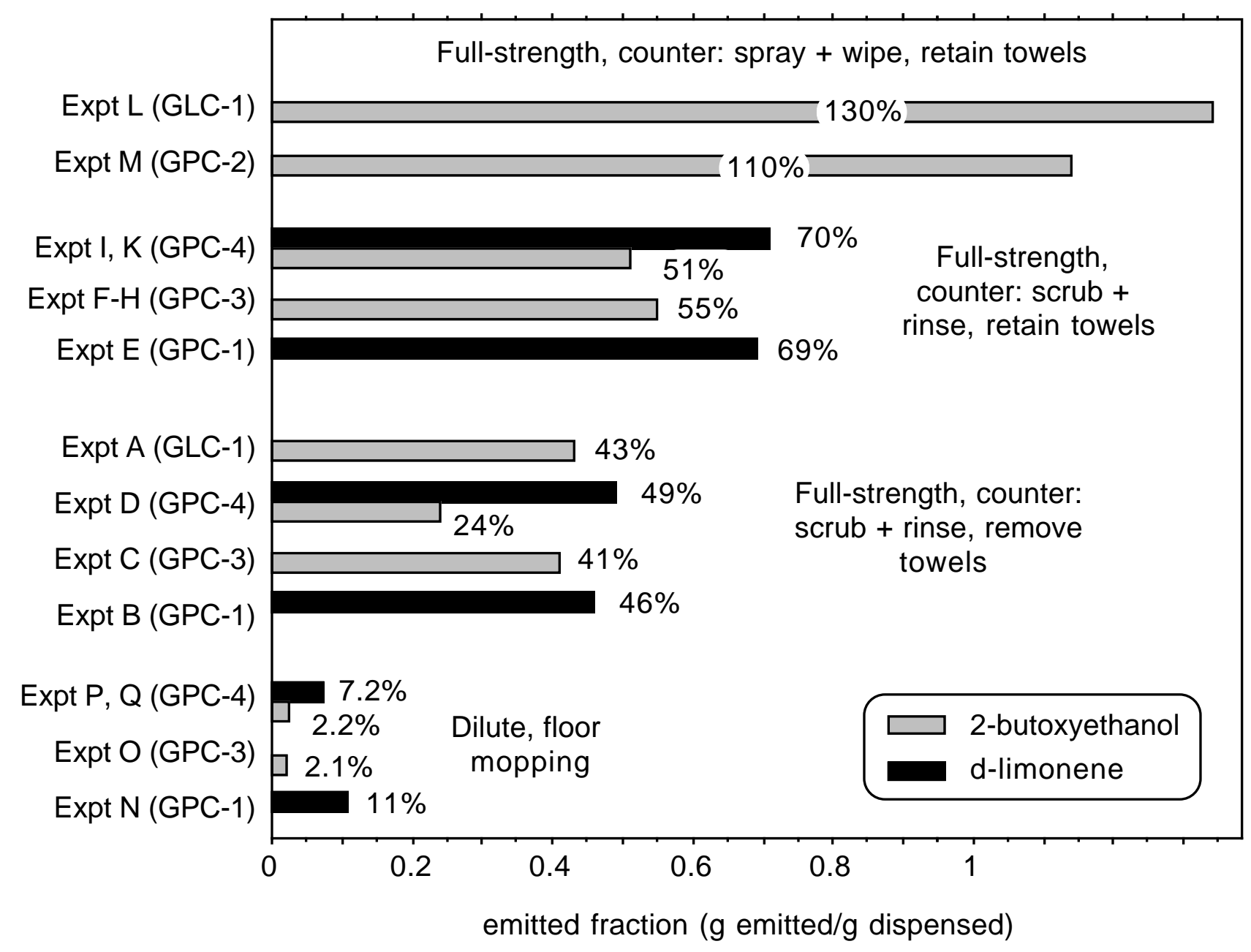




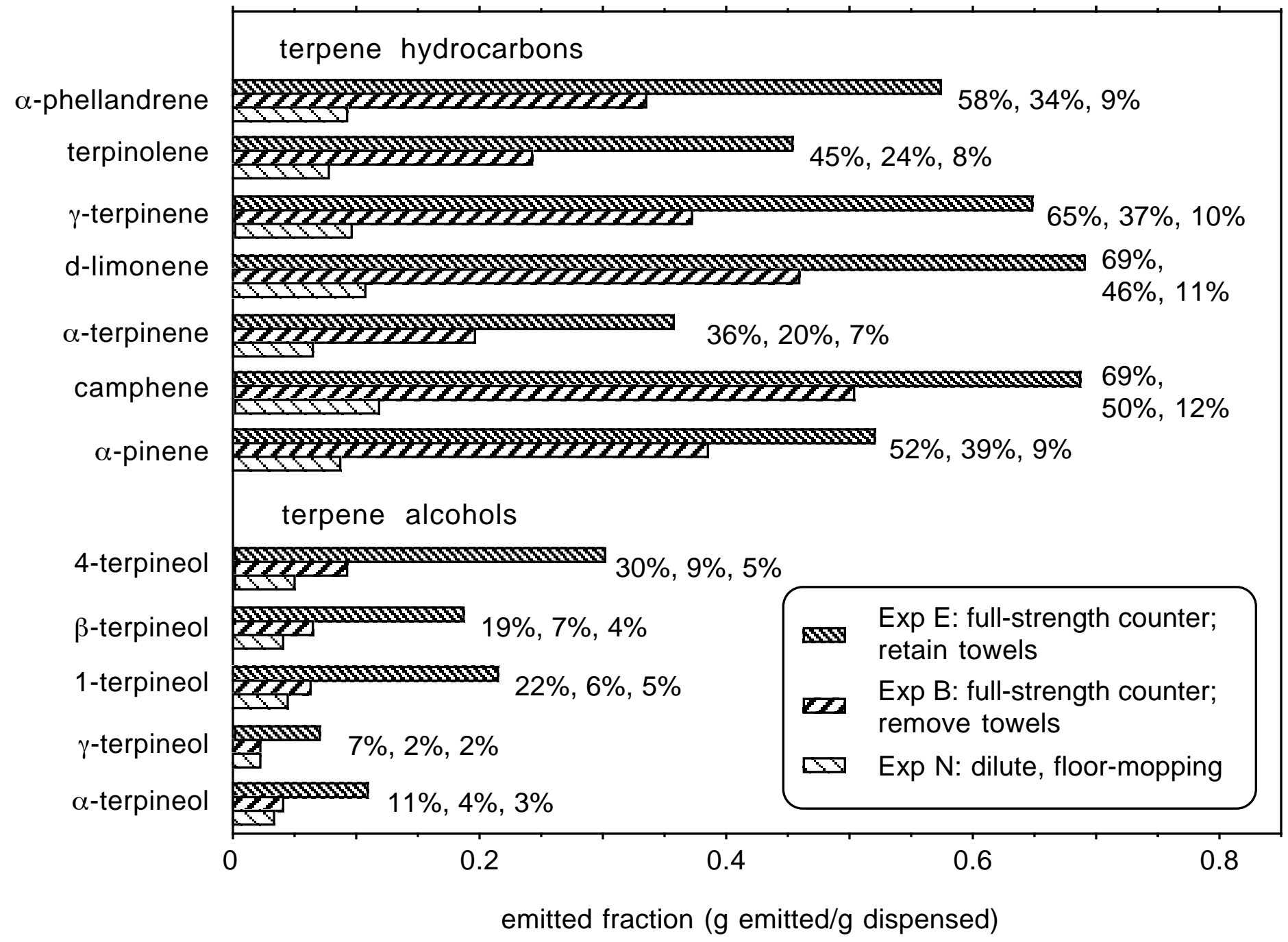

